\title{
Saberes Docentes relacionados às Tecnologias na formação de professores de Música
}

\author{
MATHEUS HENRIQUE DE FONSECA BARROS \\ CRISTIANE MARIA GALDINO DE ALMEIDA
}

Matheus Henrique da Fonsêca Barros é Doutorando em Música (Educação Musical) pela Universidade Federal da Paraíba (UFPB) e Visiting Scholar na University of Delaware (UD). Mestre em Educação pela Universidade Federal de Pernambuco (UFPE). Professor do Instituto Federal do Sertão Pernambucano no curso de Licenciatura em Música. Atua na área de Música, com ênfase em Educação Musical, nos seguintes temas: formação de professores de música; educação musical e tecnologias; problem based learning; metodologias ativas. (<http://lattes.cnpq.br/1661451730114307>)

AFILIAÇÃO: Universidade Federal da Paraíba, João Pessoa, Paraíba

Cristiane Maria Galdino de Almeida é Doutora em Música - Educação Musical pela Universidade Federal do Rio Grande do Sul (UFRGS). Professora do Departamento de Música da Universidade Federal de Pernambuco (UFPE), atuando no curso de Licenciatura em Música. Professora permanente do Programa de Pós-Graduação em Música da UFPE e UFPB. Atua na área de Música, com ênfase em Educação Musical, principalmente nos seguintes temas: formação de professores; educação musical não-formal; educação musical e etnomusicologia; e formação de professores de música e diversidade. (<http://lattes.cnpq.br/7567236180576595>)

AFILIAÇÃO: Instituto Federal do Sertão - PE. 


\section{- RESUMO}

Este artigo apresenta resultados de uma pesquisa de mestrado cujo objetivo foi compreender como os saberes relacionados às tecnologias digitais de informação e comunicação (TDIC) são construídos pelos professores da licenciatura em música da Universidade Federal de Pernambuco (UFPE). Os participantes da pesquisa foram três docentes indicados pelos estudantes. Os dados analisados qualitativamente indicaram que os saberes docentes relacionados às TDIC são construídos por professores Imigrantes Digitais, propiciando uma visão e prática instrumentalistas da tecnologia, que reconhecem sua importância no processo de formação inicial docente em música. Os saberes construídos, em sua maioria, podem ser considerados experienciais e resultam da formação inicial dos docentes, das demandas do corpo discente, constituído por Nativos Digitais, e da documentação que fundamenta suas práticas.

\section{PALAVRAS-CHAVE}

Formação de professores de música, TDIC, saberes docentes.

\section{ABSTRACT}

This paper presents the results of a Master's Degree research, which aimed at understanding how knowledge related to digital information and communication technologies (DICT) is constructed by professors of undergraduate degree in music at the University of Pernambuco (UFPE). Three professors, nominated by the students, took part in the research. The data underwent a qualitative analysis. We concluded that the faculty knowledge related to DICT, in the presented context, is constructed by Digital-Immigrant-Professors, who provide an instrumentalist view and practice of technology without, however, failing to recognize the importance of those in the process of initial teacher training in music. The knowledge built, in most cases, can be considered experiential and is the result of initial teacher training, as well as the demands of the students - which is formed by Digital Natives - and documentation that grounds their practices.

\section{KEYWORDS}

Music teacher training, DICT, knowledge base. 


\section{Introdução}

A formação inicial dos professores de música tem sido ponto de diversos debates e discussões, que se intensificaram após a aprovação da lei 11.769/2008 ${ }^{1}$ que propõe a obrigatoriedade da Música como conteúdo nas escolas da Educação Básica. Assim, é necessária uma compreensão ampla desse processo formativo, considerando as diversas concepções para o mesmo (PIRES, 2003, p. 82).

É no período de formação inicial que guardamos referências profissionais docentes que nos influenciarão durante toda nossa carreira. As ações, atitudes, preferências e práticas dos formadores serão certamente reproduzidas pelos licenciandos em algum momento de seu caminho profissional. Isso se dá, segundo Tardif (2014, p. 49-50), porque a atividade docente "é realizada concretamente numa rede de interações com outras pessoas".

A prática profissional docente, nessa "rede de interações", nos levou a perceber a importância de subsídios quanto às tecnologias no período de formação inicial. Esses recursos tecnológicos são, atualmente, denominados de Tecnologias Digitais de Informação e Comunicação (TDIC²) e "diz[em] respeito aos procedimentos, métodos e equipamentos que são usados para o processamento de informações e sua comunicação aos interessados" (CORREIA; SANTOS, 2013, p. 4). Salientamos que a inserção da tecnologia na formação do professor de música já está prevista nas diretrizes para o período formativo desde o ano de 2004 (BRASIL, 2004, p. 10).

Observando esses contextos, desenvolvemos uma pesquisa que procurou compreender como os saberes relacionados às TDIC são construídos pelos professores do curso de licenciatura em música da Universidade Federal de Pernambuco (UFPE). Mais especificamente, buscamos identificar quais são os saberes mobilizados pelos professores quando utilizam as TDIC em sua prática pedagógica; identificar, nos documentos norteadores da prática pedagógica (projeto pedagógico de curso; programas de disciplina), a presença das TDIC; e analisar as concepções dos professores quanto à importância das TDIC na formação docente em Música.

Neste artigo, pretendemos apresentar os resultados da investigação realizada, no intuito de contribuir para a discussão sobre a formação de professores de música e os saberes relacionados às TDIC. Para isso, estruturamos o texto como segue: uma breve discussão sobre saberes docentes e tecnologias; análise dos achados da pesquisa incluindo a formação inicial dos professores e sua influência na prática docente; a relação pessoal dos professores com a tecnologia; a inserção das TDIC na formação docente em Música; e, por fim, os saberes mobilizados pelos docentes, no que se refere às tecnologias, e sua relação com os documentos norteadores.

\section{Saberes docentes e Tecnologias}

Para discutir sobre formação docente e tecnologias, o aporte teórico incluiu alguns estudos relativos aos Saberes Docentes, além daqueles que versavam sobre

\footnotetext{
${ }^{1}$ A Lei $11.769 / 2008$ foi atualizada pela Lei 13.278/2016 que inclui as quatro linguagens artísticas (artes visuais, dança, música e teatro) nos currículos dos diversos níveis da educação básica.

2 Neste artigo serão mantidos os termos TDIC ou TIC - Tecnologias de Informação e Comunicação -, em respeito aos escritos originais dos autores citados.
}

ouvirouver Uberlândia v. 15 n. 1 p. 30-42 jan. |jun. 2019 
assuntos relacionados às TDIC. Tais decisões foram balizadas pelo entendimento que temos de que o contexto de mudanças estimuladas pelo avanço tecnológico promoveu impactos em toda a sociedade, e por consequência, nos processos de ensino e aprendizagem, além de exigir novas habilidades e uma mobilização diferenciada dos saberes por parte dos atores desses processos.

Os questionamentos propostos por Tardif (2014) na elaboração dessa perspectiva teórica se apresentaram também como fatores motivadores na construção do suporte teórico, entre eles, "Quais são os saberes que servem de base ao ofício de professor? [...] quais são os conhecimentos, o saber-fazer, as competências e as habilidades que os professores mobilizam diariamente [...] a fim de realizar concretamente as suas diversas tarefas?" (TARDIF, 2014, p. 9).

Os estudos sobre saberes docentes foram desenvolvidos por Tardif (2014) que, inicialmente, destaca a existência de quatro tipos: os saberes da formação profissional; os saberes disciplinares; os saberes curriculares e os saberes experienciais. Os saberes da formação profissional são um conjunto de saberes que, baseados nas ciências e na erudição, são transmitidos aos professores durante o processo de formação profissional inicial e/ou continuada pelas instituições de formação, tais quais as faculdades de educação ou universidades (TARDIF, 2014, p. 37).

A prática docente também inclui os saberes sociais gerenciados pela instituição universitária. Tardif (2014) define estes como os saberes disciplinares, que são reconhecidos e identificados como pertencentes aos diferentes campos do conhecimento. Os saberes curriculares, por sua vez, são conhecimentos apropriados que estão relacionados à forma como as instituições educacionais fazem a categorização e apresentação dos saberes sociais por ela definidos e selecionados. Por fim, os saberes experienciais são aqueles saberes específicos que resultam do exercício da atividade profissional desenvolvido cotidianamente pelos professores, apresentados pelo autor como "conjunto dos saberes atualizados, adquiridos e necessários à prática docente e que não provém das instituições e dos currículos" (TARDIF, 2014, p. 49).

Por outro lado, a discussão abordou as TDIC, que apresentam muitas possibilidades de definições e conceituações, consequência do vertiginoso e constante desenvolvimento que esse campo experimentou. Fazemos parte dessa comunidade denominada de Sociedade da Informação e, nela, o desafio de ser professor aumenta, uma vez "que os alunos do século XXI têm novas características e exigências" (FREITAS, 2009, p. 1). Esses alunos "passaram a vida inteira cercados e usando computadores, vídeo games, tocadores de música digitais, câmeras de vídeo, telefones celulares, e todos os outros brinquedos e ferramentas da era digital" (PRENSKY, 2001, p. 1).

Diante deste cenário, faz-se necessário repensar os processos formativos de professores e a inserção, presença e diálogo com as TDIC nos mesmos, uma vez que, em decorrência dessas mudanças, as sociedades têm modificado seus ideais, valores e necessidades (SANTOS, 2013). Nesse sentido, Kenski (2013, p. 95) defende que a formação docente para uma atuação efetiva na atualidade necessita de mudanças estruturais para o desenvolvimento de novas práticas profissionais, conceitos e cultura. 
Foi a partir dessas reflexões teóricas, que nos debruçamos sobre os achados da pesquisa, que serão socializados a seguir, iniciando com as relações que se estabelecem entre a formação inicial e a prática docente.

\section{Formação inicial e sua influência na prática docente}

A pesquisa se configurou como um Estudo de Casos Múltiplos (YIN, 2005), com abordagem qualitativa, tendo como participantes 3 (três) professores integrantes do corpo docente do referido curso, indicados pelos estudantes como referência na utilização das TDIC em suas práticas cotidianas, e denominados, neste texto, como Professora A, Professor B e Professor C. Para a produção dos dados, foram realizadas entrevistas semiestruturadas, análise documental dos programas das disciplinas ministradas pelos referidos professores e do Projeto Pedagógico de Curso (Perfil 8804-1 e Perfil 8805).

No que se refere à formação inicial e sua influência na prática docente, observamos que os entrevistados apresentam características semelhantes àquelas encontradas em outros cursos de graduação em Música. Os Professores A e B são bacharéis em Música e o Professor $\mathrm{C}$, licenciado em Música. Quanto à formação continuada, a Professora A fez mestrado em Música, e os Professores B e C são doutores na área de Música, mas nenhuma das titulações foi realizada na subárea da Educação Musical.

No campo da Música, não é rara a situação de bacharéis lecionando nos mais diversos níveis de ensino. Tal fato é atestado por Penna (2007, p. 51), ao afirmar que "muitas vezes bacharéis, ou mesmo músicos com as mais variadas formações, atuam como educadores musicais". Torna-se importante ressaltar que "grande parte dos cursos de bacharelado em música [...] não oferece formação pedagógica, ou seja, não os habilita para a docência na área" (WEBER; GARBOSA, 2015, p. 90). Por essa razão, a atuação docente acaba aparecendo como desdobramento do caminhar musical na performance, e não como projeto inicial de carreira.

Muito embora os casos apresentados nesta pesquisa sejam de professores da rede federal de ensino, da carreira de magistério superior, regida pela Lei 12.772/2012, que não indica a necessidade de formação inicial na área de licenciatura para o exercício da profissão, entendemos que esse aspecto contribui para as reflexões sobre a formação de professores para atuação em todos os níveis de ensino.

Esse percurso de formação está intrinsecamente associado ao modelo tradicional de ensino de música, também conhecido como modelo conservatorial, "presente principalmente nas escolas especializadas - conservatórios, bacharelados e pós-graduações” (PENNA, 2007, p. 51). Tal modelo dá ênfase ao domínio da leitura e da escrita musicais, assim como da técnica instrumental, que, por sua vez, tem como meta o "virtuosismo" (SANTOS, 2001).

$\mathrm{Na}$ prática docente do professor de música, os conhecimentos específicos precisam estar associados aos saberes disciplinares e aos saberes pedagógicos, na perspectiva proposta por Tardif (2014). Não se pode conceber um professor que domine os conhecimentos específicos de sua área de conhecimento sem uma consistente formação pedagógica, a qual se torna insuficiente sem o domínio do conhecimento específico, tal qual proposto por Gauthier e colaboradores (1998). 
A compreensão dos saberes pedagógicos se mostra tão importante quanto os conhecimentos musicais específicos, entendendo que ambos são fundamentais para a prática profissional docente em Música. Como indica Del-Ben (2003, p. 31), "para ensinar música [...] não é suficiente somente saber música ou somente saber ensinar. Conhecimentos pedagógicos e musicológicos são igualmente necessários, não sendo possível priorizar um em detrimento do outro". Essa discussão é aprofundada pela autora com a colaboração de Hentschke, Almeida e Azevedo (2006, p. 657), quando afirmam que "se necessitamos dos saberes pedagógicos para a docência de música, eles se tornam saberes específicos da educação musical". Por isso, é impositiva "a necessidade de não mais concebê-los como externos ao nosso campo ou somente tomá-los por empréstimo. Ao se tornarem específicos, talvez assumam especificidades próprias da área de música" (DEL-BEN; HENTSCHKE; ALMEIDA; AZEVEDO, 2006, p. 657).

Ao analisar a formação inicial dos docentes integrantes da pesquisa, em um curso de bacharelado, evidenciamos que esse percurso formativo demandou, dos Professores A e B, o desenvolvimento de conhecimentos necessários ao ofício docente, por meio da experiência profissional e do saber experiencial, como explicitado no depoimento dado pela Professora A:

Porque eu fiz bacharelado, nunca... não fui para a faculdade para fazer licenciatura, eu não tinha essa intenção, mas, enfim, por outros caminhos você acaba chegando no mesmo lugar. E aí quando eu saí da faculdade e fui fazer o mestrado, abre uma vaga para professor substituto, lá na [Universidade] de percepção e aí eu fui dar aula, também, como professora substituta. (CE ${ }^{3}$ 1, p. 2).

Esse "saber interativo, mobilizado e modelado no âmbito das interações entre o professor e os outros atores educativos" (TARDIF, 2014, p. 109) toma uma dimensão ainda mais importante em nossa análise, por ocorrer no âmbito de um curso de formação de professores de música. Essa relação com os saberes da experiência se estende também ao Professor $\mathrm{C}$ que, de maneira distinta, inseriu em sua prática, "esse saber aberto, poroso, permeável, pois integra experiências novas adquiridas ao longo do caminho" (TARDIF, 2014, p. 109). Vale ressaltar sua experiência no ensino em escolas de ensino fundamental e médio, elemento vital nessa composição de sua formação. Assim, o Professor $C$ pôde mobilizar também os saberes pedagógicos, curriculares e disciplinares, uma vez que tais saberes fizeram parte de sua formação inicial (licenciatura).

\section{Tecnologia: relação pessoal, conceito e possibilidades}

No que diz respeito às tecnologias, foi interessante perceber que esses professores não se consideravam "usuários ávidos dos dispositivos tecnológicos", muito embora tenham sido apontados pelos estudantes como referência na utilização dos mesmos. Essa inferência se realiza quando a Professora $A$ afirma que não tem uma relação de paixão por equipamentos tecnológicos, restringindo seu uso às

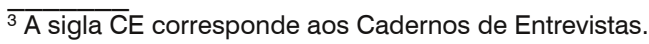


redes sociais, celular e computador (CE 1, p. 3). Embora em sua dinâmica de trabaIho, a tecnologia esteja sempre incluída, não só por ser sua área de atuação e pesquisa, o Professor $\mathrm{C}$, por opção, procura não utilizar dispositivos tecnológicos em sua vida pessoal e não se interessa pelo uso de redes sociais (CE 3, p. 3).

A sua indicação pelos discentes como referência na lida com as tecnologias causou surpresa ao Professor $B$, que ressaltou sua pouca relação pessoal com as mesmas: "Para te falar a verdade até fiquei muito espantado porque [...] não sou especialmente adepto à tecnologia" (CE 2, p. 2). O Professor B também não utiliza redes sociais: "Eu sou uma criatura, por exemplo, que não entra em rede social, muito pouco" (CE 2, p. 18), além de entender que "o computador, no fundo, no fundo, não passa de uma máquina de escrever sofisticadíssima que eu subutilizo, mas confesso, que isso não tenho medo nenhum de confessar, [...] eu também faço parte de uma outra geração" (CE 2, p. 18).

O fato de os professores serem "parte de outra geração", não tão afeita ao mundo tecnológico, faz-nos recorrer a dois conceitos trabalhados por Prensky (2001): Nativos Digitais e Imigrantes Digitais. Para o autor, há uma dicotomia clara entre duas gerações representadas pelos dois conceitos propostos, conviventes nas mais diversas atividades, inclusive no ensino.

O autor aponta que a geração dos Nativos Digitais é possuidora de características diferentes das gerações anteriores: vivem constantemente conectados com seus pares, através das mais diversas possibilidades (computador, celulares, redes sociais), "estão acostumados a receber informações muito rapidamente. Além disso, eles gostam de processar mais de uma coisa por vez e realizar múltiplas tarefas" (PRENSKY, 2001, p. 2). Eles estão acostumados à rapidez do hipertexto, baixar músicas, e ter disponível um mundo de possibilidades em seus smartphones (PRENSKY, 2001).

Do outro lado, existem aquelas pessoas que "aprenderam a usar as tecnologias digitais ao longo de suas vidas adultas" (PESCADOR, 2010, n.p.), os Imigrantes Digitais. Prensky (2001, p. 3) destaca que "como os Imigrantes Digitais aprendem [...] a adaptar-se ao ambiente, eles sempre mantêm, em certo grau, seu 'sotaque'. Este sotaque "pode ser percebido de diversos modos, como o acesso à internet para a obtenção de informações, ou a leitura de um manual para um programa ao invés de assumir que o programa nos ensinará como utilizá-lo" (PRENSKY, 2001, p. 3). Mesmo estando de forma mais efetiva em um dos grupos apresentados, pudemos perceber que as tecnologias estão no cotidiano de todos, porém ainda não se mostram completamente integradas à prática docente.

As características dessa geração de Nativos Digitais são percebidas também pelos entrevistados. A Professora A sinaliza que a maior parte dos estudantes atuais detém um conhecimento tecnológico mais avançado do que os professores (CE 1, p. 8), enquanto o Professor B assume, em seu depoimento, essas diferenças:

Os meus alunos, às vezes eu ligo o computador aqui e fico que nem um boboca procurando onde é que estão as coisas e os alunos gritando lá no fundo da sala, professor à esquerda, ali, não sei onde. $\mathrm{E}$ eu, né. É... Enfim, não tenho o menor problema de confessar a eles que eu não... Nesse aspecto eles são muito melhores do que eu. Sabem muito mais. (CE 2, p. 10). 
Outro aspecto identificado nos três docentes diz respeito à utilização dos aparatos tecnológicos em sala de aula. Todos foram unânimes em expressar o entendimento das tecnologias como um instrumento ou ferramenta a serviço de algo. Para a professora $A$, tecnologia é "tudo aquilo que pode ser tido como suporte ao seu trabalho" (CE 1, p. 2). O Professor B, por sua vez, entende que "a tecnologia é um instrumento através do qual [com ênfase] o exercício de uma determinada atividade pode ser extremamente facilitado" (CE 2, p. 11). Acompanhando a mesma ideia, o Professor $\mathrm{C}$ afirma: "é uma ferramenta muito boa [...] é uma ferramenta fantástica, eu acho que tem que ser utilizada" (CE 3, p. 9, grifo nosso).

Essa concepção de tecnologia como ferramenta é discutida por Peixoto (2009). Para a autora, existe uma lógica instrumentalista, quando tecnologia e educação estão relacionadas, que entende "as tecnologias como meios facilitadores da aprendizagem e também da tarefa do professor" (PEIXOTO, 2009, p. 221). Os discursos que carregam essa concepção se apoiam no paradigma construtivista "ao indicar os recursos tecnológicos como instrumentos mediadores do processo de aprendizagem, [entendendo sempre] a tecnologia como algo flexível, modelado pela prática dos usuários" (PEIXOTO, 2009, p. 221). Porém, o que se observa com a integração das tecnologias aos processos pedagógicos é a ampliação das "exigências feitas tanto ao aluno quanto ao professor" (PEIXOTO, 2009, p. 221). Além disso, Peixoto (2009, p. 219-220) ressalta que as tecnologias não têm "capacidade de provocar mudanças sócio-organizacionais políticas e culturais por si mesma".

Inferimos, assim, que a visão da tecnologia como mero instrumento ou recurso didático é oriunda de uma construção de conhecimento tecnológico na perspectiva de Imigrantes Digitais. Muito embora haja a tentativa em se apropriar das tecnologias, os Imigrantes Digitais nunca serão iguais aos Nativos Digitais, e os seus "sotaques" serão sempre percebidos.

\section{TDIC e formação docente em Música}

Os docentes atestam a necessidade e a importância da presença das TDIC na formação do professor de música, quando fazem as seguintes afirmativas: "Eu acho que hoje não tem mais como você abrir mão dessas tecnologias" (Professora A, CE 1, p. 8). "A tecnologia é algo que veio para ficar, está aí, isso é indiscutível e nós temos que aprender a lidar com ela" (Professor B, CE 2, p. 12).

Isso é decorrente do entendimento e da percepção de um mundo completamente imerso no meio digital, fazendo com que: i) as gerações mais jovens, que já convivem com esse meio, cheguem aos programas de formação de professores, o que promove o repensar de suas práticas como docentes; ii) a consciência de que esses futuros professores precisam estar aptos a responder às exigências de uma geração ainda mais jovem quando no futuro exercício de sua prática profissional.

Portanto, um curso de licenciatura nos dias atuais deve promover a reflexão que ajude a compreender a relação cada vez mais próxima dos estudantes que já nasceram em um mundo permeado de tecnologias digitais, ressaltando a importância do diálogo com as mesmas, proporcionando o desenvolvimento de novas metodologias mais adequadas ao momento histórico vivido. A Professora A percebe 
alguns desses impactos e indica possibilidades, tais quais o uso dos celulares como instrumentos musicais através de aplicativos, a interação através das redes sociais e internet, apontando que podem, inclusive, vencer o obstáculo do espaço físico necessário para a prática de atividades musicais (CE 1, p. 8). Vale lembrar que diversos aplicativos têm sido desenvolvidos para a produção e aprendizagem musical, como também a popularização dos Podcast e serviços de Streaming, onde se buscam e compartilham suas listas de preferências musicais colaborativamente.

A apropriação das TDIC por partes dos cursos de licenciatura em música deve ser "mais que o acesso e o conhecimento técnico-operacional dos mesmos" (LEME; BELLOCHIO, 2007, p. 89). No entanto, para que ocorra o avanço em relação à lógica instrumentalista, "é preciso que o professor aprenda, inicialmente, a lidar com os recursos tecnológicos que escolhe, ou que precisa aprender, para poder empregá-los em relação a um fazer musical significativo para ele e para os seus alunos" (LEME; BELLOCHIO, 2007, p. 89). Ainda nesse sentido, os autores atentam para o fato de que lidar com as tecnologias não traz nenhuma garantia de que o professor de música saberá como utilizá-las de modo crítico-reflexivo. Para que isso ocorra, a formação inicial deve familiarizar os alunos (futuros professores) à prática profissional reflexiva, estando "vinculada aos condicionantes e às condições reais do exercício da profissão e contribuir, assim, para a sua evolução e transformação" (TARDIF, 2014, p. 289).

Outro aspecto que se apresenta ao refletirmos sobre as TIDIC na formação de professores de música é aquele relacionado às práticas musicais. Compreendendo que as discussões teóricas apontam possibilidades e desafios aos modelos de formação musical, Araldi (2013, p. 3) destaca que uma das preocupações no ensino de Música é "compreender a forma como os alunos se relacionam com a tecnologia e quais as mudanças na pedagogia musical geradas pelos avanços tecnológicos" Essa preocupação é expressa pelo Professor C que pondera: "Então, ou você acompanha o nível da galera ou você vai ficar para trás, eu acho que o primeiro incentivo do professor é isso, eu tenho que entender que essa coisa existe". (CE 3, p. 15).

Vale observar que o avanço e popularização das TDIC possibilitaram também o surgimento de novas estéticas musicais, influenciando na forma de ouvir, compor e se relacionar com a música. No entanto, o modelo conservatorial ainda é hegemônico na construção curricular também dos cursos de licenciatura (ver PEREIRA, 2014), não valorizando os discursos musicais gerados a partir das TDIC. Para alterar essa situação, os cursos de formação de professores necessitam privilegiar todos os aspectos musicais, incluindo a música contemporânea (potencializada pelas TDIC) e não apenas as músicas do modelo tonal. Além disso,

[...] para que o estudante de licenciatura possa compreender o papel das transformações tecnológicas na sua formação pedagógica e na vida de seus alunos, é necessário que se estude sobre os impactos na pedagogia musical, bem como problematizar o papel das transformações tecnológicas nos diferentes ambientes de ensino em que vai atuar. (ARALDI, 2013, p. 5). 
Essa problematização ficou evidente no discurso dos professores em vários momentos. Eles demonstraram preocupações relevantes no que tange à importância das TDIC na formação docente em Música e procuraram desenvolver práticas que propiciassem a presença das tecnologias, entendendo que é no processo de formação que muitos problemas podem ser resolvidos. Contudo, as ações promovidas pelos professores ainda são permeadas por uma visão instrumentalista das tecnologias. Tal concepção apareceu, também, no momento em que os docentes indicaram a necessidade de melhorias na infraestrutura do curso, como um fato que acarretaria em uma apropriação mais efetiva das TDIC na formação, bem como o oferecimento de novas modalidades de ensino, como o Ensino a Distância (EAD).

\section{Saberes mobilizados, TDIC e sua relação com os documentos norteadores}

As motivações observadas nos depoimentos dos docentes para justificar a presença das TDIC em suas práticas foram a facilitação do trabalho docente e o reconhecimento de mundo digital. No entanto, os saberes mobilizados em suas práticas nem sempre se conectam com os princípios e as metas dispostos no(s) Projeto(s) Pedagógico(s) de Curso. Isso fica demonstrado, especialmente, no discurso de dois dos professores pesquisados que nos permitiram inferir que não possuem uma compreensão profunda da amplitude dos documentos norteadores da prática docente.

Há um entendimento, por parte dos pesquisados, de que esses documentos são a representação de uma disfunção burocrática. O Professor B ressalta: "eu sou a favor de uma educação objetiva [...] nós temos que ser muito objetivos, nós temos muita informação para manipular, e, portanto, a objetividade é fundamental" (CE 2, p. 14). Essa concepção inclui também o Professor $C$ (licenciado em música) que afirmou: "Essa é a pior parte para mim, burocracia" (CE 3, p. 12).

Por entender que esses documentos são elementos que têm conexão direta com o trabalho dos professores pesquisados, consideramos que a presença ainda insignificante de elementos relacionados às TDIC na documentação é preocupante, especialmente quando nos reportamos para a importância das TDIC na formação do professor de música em uma sociedade de nativos digitais. O Perfil 8804-1 não faz menção às TDIC em nenhuma das suas seções, nem mesmo nos programas de disciplina ${ }^{4}$ ou em aspectos de direcionamento metodológico.

No Perfil 8805 existem menções mais específicas ao longo de suas seções. Porém, nos programas de disciplina analisados, percebemos uma presença tímida das TDIC. A parte da Metodologia dá algumas indicações de utilização de instrumento ou aparato tecnológico. Expressões como "Audições comentadas de áudio/vídeo de repertório variado", "Aulas expositivas, no formato multimídia", evidenciam uma predominância das tecnologias audiovisuais. Os programas não apresentam se os trabalhos ou projetos decorrentes da dinâmica e avaliação das disciplinas são entregues utilizando a internet ou sistemas de armazenamento virtual nem se a comunicação entre os professores e a turma fora do ambiente de sala de aula é feita utilizando algumas das redes ou mídias sociais. Também não há menção

\footnotetext{
$\overline{4}$ Exceção feita pela disciplina "MU678 - Sequenciamento MIDI", cujo tema e conteúdos é a utilização de softwares para gravação e que começou a ser válida somente a partir do primeiro semestre do ano 2000.
} 
ou previsão de alguma experiência em EAD ou da utilização de softwares mais específicos, embora esses aspectos sejam abordados em suas falas durante a entrevista (CE 3, p. 3-4).

Apesar disso, compreendemos que a pouca presença de elemento relacionados às TDIC nos documentos pode contribuir para a mobilização e construção dos saberes na prática (experienciais e pedagógicos). Esse fato fica evidenciado quando um dos professores informou ter buscado o conhecimento teórico-prático por meio de pesquisas acadêmicas desenvolvidas sobre as tecnologias na educação.

Há uma clara evolução na concepção do Projeto Pedagógico de Curso atual (Perfil 8805), materializada por meio de uma melhor estruturação, além de justificativas e referencial teórico bem definidos. No entanto, ainda existe uma dificuldade relativa ao fato de professores e discentes estarem sob a égide de documentos com origens temporais tão diferentes ${ }^{5}$. Pudemos observar também que os demais saberes, tais quais os saberes da formação profissional, saberes disciplinares e saberes curriculares (TARDIF, 2014), permeiam os documentos. Esses saberes são ressignificados na prática, a partir das experiências dos professores pesquisados, resultando então nos saberes experienciais.

\section{Considerações Finais}

Ao final do processo de pesquisa, pudemos concluir que os saberes docentes relacionados às TDIC, no contexto do curso de Licenciatura em Música da UFPB, são construídos por professores Imigrantes Digitais, ou seja, sujeitos que procuram se apropriar das tecnologias, mas que terão os seus "sotaques" sempre percebidos. Isto propicia uma visão prática e instrumentalista da tecnologia, que tem como premissa a facilitação do trabalho docente e o reconhecimento de mundo digital, mas que acaba por não permitir o entendimento da tecnologia como conhecimento específico da música.

No entanto, os docentes demonstram perceber a importância das tecnologias no processo de formação inicial do professor de música, entendendo que é nesse momento que muitos problemas podem ser resolvidos. Esse entendimento pode ser inferido nas tentativas de diálogos, a partir de uma mesma linguagem em termos de mundo digital, como o desenvolvimento de práticas que propiciem a presença das tecnologias, além do processo de mudanças metodológicas no decorrer das disciplinas.

Os saberes construídos, em sua maioria, podem ser considerados experienciais e são resultado da formação inicial dos docentes, da documentação que fundamenta suas práticas e das demandas do corpo discente, que é constituído, em sua maioria, por Nativos Digitais. Essa documentação, contudo, não apresenta uma presença efetiva das TDIC, apesar de evidenciar uma significativa evolução na construção e concepção da mesma.

Assim, reforçamos a necessidade de aprofundarmos as discussões sobre os saberes necessários para a consolidação da profissão docente nos dias atuais, o que inclui a reflexão sobre os processos de formação inicial de professores de música, em uma sociedade cada vez mais tecnológica.

\footnotetext{
${ }^{5}$ Há uma separação de quase quinze anos desde as últimas reformas feitas no Perfil 8804-1 para a elaboração e implementação de Perfil 8805, o que mostra uma discrepância quanto a discursos, fundamentações, concepções e, principalmente, no que diz respeito à presença e utilização das TDIC.
} 


\section{REFERÊNCIAS}

ALMEIDA, P. C. A.; BIAJONE, J. Saberes docentes e formação inicial de professores: implicações e desafios para as propostas de formação. Revista Educação e Pesquisa, [online], v. 33, n. 2, p. 281-295, maio/ago. 2007.

ARALDI, J. Transformações tecnológicas e desafios na formação e atuação de professores de música. Hipertextus Revista Digital, v. 11, dez. 2013. Acesso em: 20 jan. 2016.

BRASIL. Conselho Nacional de Educação. Resolução CNE/CES 2/2004. Brasília, 2004.

CORREIA, R. L.; SANTOS, J. G. A Importância da Tecnologia da Informação e Comunicação (TIC) na Educação a Distância (EAD) do Ensino Superior (IES). Revista Aprendizagem em EAD, Taguatinga, v. 2, p. 1-16, nov. 2013.

DEL BEN, L. Ensino de Música: propostas para pensar e agir em sala de aula. São Paulo: Moderna, 2003.

DEL BEN, L.; HENTSCHKE, L.; ALMEIDA, C. M. G.; AZEVEDO, M. C. C. C. Saberes pedagógicos ou específicos? uma discussão sobre os saberes no campo da educação musical. In: ENCONTRO ANUAL DA ASSOCIAÇÃO BRASILEIRA DE EDUCAÇÃO MUSICAL, 15., 2006, João Pessoa. Anais... João Pessoa: 2006, p. 652-659.

FREITAS, M. T. A. Janela sobre a utopia: computador e internet a partir do olhar da abordagem históricocultural. In: REUNIÃO ANUAL DA ASSOCIAÇÃO NACIONAL DE PÓS-GRADUAÇÃO E PESQUISA EM EDUCAÇÃO, 32., 2009, Caxambu. Anais... Caxambu: ANPEd, 2009, p. 1-14.

GAUTHIER, C. et al. Por uma teoria da pedagogia: pesquisas contemporâneas sobre o saber docente. ljuí: Unijuí, 1998.

KENSKI, V. M. Tecnologias e tempo docente. Campinas: Papirus, 2013.

LEME, G. R.; BELOCHIO, C. R. Professores de escolas de música: um estudo sobre a utilização de tecnologias. Revista da ABEM, Porto Alegre, n. 17, p. 87-96, set. 2007.

PENNA, M. Não basta tocar? Discutindo a formação do educador musical. Revista da ABEM, Porto Alegre, v. 16, p. 49-56, mar. 2007.

PEREIRA, M. V. M. Licenciatura em música e habitus conservatorial: analisando o currículo. Revista da ABEM, Londrina, v. 22, n. 32, p. 90-103, jan./jun. 2014.

PESCADOR, C. M. Tecnologias digitais e ações de aprendizagem dos nativos digitais. In: CONGRESSO INTERNACIONAL DE FILOSOFIA E EDUCAÇÃO, 5., 2010, Caxias do Sul. Anais... Caxias do Sul: 2010, n.p.

PIRES, N. A identidade das licenciaturas na área de música: multiplicidade e hierarquia. Revista da 
ABEM, Porto Alegre, v. 9, p. 81-88, set. 2003.

PRENSKY, M. Digital Natives, Digital Immigrants. MCB University Press, 2001. Disponível em: <https://www.marcprensky.com/writing/Prensky\%20-\%20Digital\%20Natives,\%20Digital\%20lmmigrants\%20-\%20Part1.pdf>. Acesso em: 03 jan. 2016.

SANTOS, A. H. A Formação Tecnológica dos Alunos dos Cursos de Licenciatura em Música - Pesquisa em Andamento. In: CONGRESSO NACIONAL DA ASSOCIAÇÃO BRASILEIRA DE EDUCAÇÃO MUSICAL, 21., 2013, Pirenópolis. Anais... Pirenópolis: 2013, p. 191-199.

SANTOS, R. M. S. Jaques-Dalcroze, avaliador da instituição escolar: em que se pode reconhecer Dalcroze um século depois? Debates - Caderno do Programa de Pós-Graduação em Música, Rio de Janeiro, n. 4, p. 7-48, 2001.

TARDIF, M. Saberes docentes e formação profissional. Petrópolis, RJ: Vozes, 2014.

WEBER, V.; GARBOSA, L. W. F. A construção da docência do professor de instrumento: um estudo com bacharéis. Revista da ABEM, Porto Alegre, v. 23, n. 35, p. 89-105, jul./dez. 2105.

YIN, R. K. Estudo de caso: planejamentos e métodos. Porto Alegre: Bookman, 2005.

Recebido em 26/02/2019 - Aprovado em 15/03/2019

Como citar:

Barros, M, H, F, e Almeida, C, M, G. (2019) Saberes docentes relacionados ás Tecnologias na formação de professores de Música. OuvirOUver, 15(1), 30-42. https://doi.org/10.14393/OUV24-v15n1a2019-2

(c) (5) \& A revista ouvirOUver está licenciada com uma Licença Creative 